OPEN ACCESS

Edited by:

Xander Wang,

University of Prince Edward Island,

Canada

Reviewed by:

Shaobo Qiao,

Sun Yat-sen University, China

Yanju Liu,

National Climate Center, China

*Correspondence:

Ruonan Zhang

rn_zhang@fudan.edu.cn

Specialty section:

This article was submitted to Interdisciplinary Climate Studies,

a section of the journal

Frontiers in Earth Science

Received: 11 August 2021

Accepted: 20 October 2021

Published: 19 November 2021

Citation:

Zhang R, Chu Q, Zuo Z and Qi Y (2021)

Summertime Moisture Sources and

Transportation Pathways for China and

Associated Atmospheric

Circulation Patterns.

Front. Earth Sci. 9:756943.

doi: 10.3389/feart.2021.756943

\section{Summertime Moisture Sources and Transportation Pathways for China and Associated Atmospheric Circulation Patterns}

\author{
Ruonan Zhang ${ }^{1,2 *}$, QuCheng $C h u^{3}$, Zhiyan Zuo ${ }^{1,2}$ and Yanjun $Q i^{4}$ \\ ${ }^{1}$ Department of Atmospheric and Oceanic Sciences, Institute of Atmospheric Sciences, Fudan University, Shanghai, China, \\ ${ }^{2}$ Innovation Center of Ocean and Atmosphere System, Zhuhai Fudan Innovation Research Institute, Zhuhai, China, ${ }^{3}$ State Key \\ Laboratory of Satellite Ocean Environment Dynamics, Second Institute of Oceanography, Ministry of Natural Resources, \\ Hangzhou, China, ${ }^{4}$ Chinese Acadamy of Meteorological Science, Beijing, China
}

Based on the Lagrangian particle dispersion model, HYSPLIT 4.9, this study analyzed the summertime atmospheric moisture sources and transportation pathways affecting six subregions across China. The sources were: Midlatitude Westerly (MLW), Siberian-Arctic regions (SibArc), Okhotsk Sea (OKS), Indian Ocean (IO), South China Sea (SCS), Pacific Ocean (PO), and China Mainland (CN). Furthermore, the relative contributions of these seven moisture sources to summertime precipitation in China were quantitatively assessed. Results showed that the $\mathrm{CN}$ precipitation source dominates the interannual and interdecadal variation of precipitation in most subregions, except Southwest and South China. The Northeast China vortex and Pacific-Japan (PJ) teleconnection, which transport water vapor from the MLW, OKS and PO sources, are crucial atmospheric systems and patterns for the variation of precipitation in Northeast China. The interannual variation of precipitation in Northwest and North China is mainly dominated by mid-highlatitude Eurasian wave trains, which provide the necessary dynamical conditions and associated moisture transport from the MLW and SibArc sources. In addition, an enhanced western North Pacific subtropical high (WNPSH) accompanied by the East Asian-western North Pacific summer monsoon and PJ teleconnection, transports extra moisture to North China from the SCS and PO sources, as well to the Yangtze River Valley and South China. The Indian summer monsoon (ISM) is also critically important for the interdecadal change in precipitation over the Yangtze River Valley and South China, via the southwesterly branch of moisture transport from the IO source. The interdecadal changes in precipitation over Southwest China are determined by the 10 and SCS sources, via enhanced WNPSH coupling with a weakened ISM. These results suggest that the interdecadal and interannual variations of moisture sources contribute to the attendant variation of summertime precipitation in China via large-scale circulation regimes in both the mid-high and lower latitudes.

Keywords: moisture source, atmospheric wave trains, east asian summer monsoon, Pacific-Japan teleconnection, Indian summer monsoon 


\section{INTRODUCTION}

Interannual and interdecadal variations of summer precipitation over China are fundamentally controlled by water vapor transport (Zhou and Yu, 2005; Zhao et al., 2007; Sun and Wang, 2011; Zhu et al., 2011), dynamically associated with large-scale atmospheric circulation in both the lower and mid-high latitudes. The major atmospheric circulation regimes affecting the East Asian moisture pathways include the East Asian summer monsoon, western North Pacific subtropical high (WNPSH), Indian summer monsoon (ISM), midlatitude westerly (MLW), and Arctic Oscillation. Specifically, the subtropical high and summer monsoon transport water vapor from the South China Sea and western Pacific through southwesterly and southeasterly moisture branches to yield precipitation over eastern China (Wang and Chen, 2012; Sun and Wang, 2014a, 2014b). The ISM is critical for summertime precipitation over Southwest China (Tian and Fan, 2013) and the semiarid regions of China (Yatagai and Yasunari, 1995), mainly through the southwesterly branch of the moisture pathway that transports water vapor from the Indian Ocean. The MLW, which transports moisture from the Eurasian continent, has an impact on the westerly branch of moisture supply to South China during summer (Simmonds et al., 1999) and to northern China during winter (Gong et al., 2001; Zhou, 2011). In high-latitude regions, Arctic sea-ice loss and the North Atlantic Oscillation have additional influence on the moisture transport over Northwest China (Liu et al., 2012; Li and Wang, 2013; Zhang and Zhou, 2015; Hua et al., 2017) and North China (Zhang et al., 2018) through large-scale Eurasian wave trains. Besides these large-scale atmospheric regimes, local evapotranspiration is another crucial source of atmospheric moisture, which accounts for approximately $9.6 \%$ of total rainfall as estimated by the global annual mean recycling (Trenberth, 1999). Numaguti (1999) demonstrated that most of the summertime precipitation over the Eurasian continent is supplied by evaporation from the continental surface. Considering the complex regime of atmospheric water vapor transport over China (Zhou and Yu, 2005), the atmospheric sources are thus differing in distinct subregions of China. Although past studies have identified various moisture sources of regional precipitation, they do not provide a complete picture of affecting factors in both the lower and mid-high latitudes.

Typically, two types of numerical models are employed to simulate the atmospheric water cycle and to trace the trajectories of air parcels. One is the conventional Eulerian method, which diagnoses local sources of precipitable moisture over a fixed region and concerns the temporal variation of a fixed air parcel. Its disadvantage is its lack of a reasonable "source-receptor" linkage between the possible moisture source and the target precipitation regions. Given this deficiency, another effective method is the Lagrangian numerical model, which traces the origins of atmospheric water and the trajectories of specific air parcels over time. The most commonly used model is the Flexible Particle Dispersion Model (Stohl and James, 2005), which has been extensively employed to study the global water cycle (Gimeno et al., 2010;
Chen et al., 2012; Chen et al., 2013; Viste and Sorteberg, 2013; Drumond et al., 2011; Sun and Wang, 2014a, Sun and Wang, 2014b). However, besides this model, the Hybrid Single-Particle Lagrangian Integrated Trajectory Model (HYSPLIT; Draxler and Hess, 1998) is helpful in studying global water vapor transport processes. For instance, Jiang et al. (2013); Jiang et al. (2017) utilized HYSPLIT to investigate water vapor transport characteristics over the Yangtze-Huaihe River valley during the mei-yu period and decadal changes in North China precipitation during the rainy season. Chen and Luo (2018) analyzed the sources and pathways of South China precipitation during the pre-summer rainy season. Chu et al. (2019) identified the role of moisture sources and transportation pathways in the variation of precipitation over East China and its linkage to tropical sea surface temperature. In the present study, HYSPLIT is employed to simulate the atmospheric moisture sources and physical pathways of summertime precipitation in six subregions across China.

Regionally speaking, most studies emphasize the moisture sources of summertime precipitation over East China (Sun and Wang, 2014b; Chu et al., 2019) and the semiarid grasslands (Yatagai and Yasunari, 1995; Huang et al., 2011; Sun and Wang, 2014a), whilst a complete picture of the moisture sources for precipitation over has yet to be thoroughly examined. Furthermore, elucidation of the possible mechanisms involved in regional precipitation variations has tended to focus on the tropical ocean and large-scale circulation systems, such as the East Asian and Indian summer monsoons and the MLW. Considering the complex atmosphere-ocean and tropics-extratropics interactions, however, current understanding of the atmospheric circulation regimes affecting subregional precipitation remains vague. Therefore, the aim of the present study was to quantitatively investigate the Northern Hemisphere atmospheric moisture sources for precipitation over the whole of China and their relative contributions to summertime precipitation over distinct subregions. Moreover, the critical atmospheric regimes acting as atmospheric bridges linking the moisture sources to the target precipitation regions were also examined.

\section{DATA AND METHODS}

Version 4.9 of HYSPLIT9, a Lagrangian particle dispersion model, was employed to trace air parcel trajectories before the air parcels arrived in target regions (Draxler and Hess, 1998). The 6-hourly and monthly geopotential height, horizontal and vertical wind, 2-m temperature, sea surface temperature, evaporation, precipitable water, and precipitation during 1979-2017, at a resolution of $1^{\circ} \times 1^{\circ}$, from the ERA-Interim reanalysis, were used as input data for the HYSPLIT model.

The air parcels in the middle and lower troposphere $(500 \mathrm{~m}$, $1,000 \mathrm{~m}, 1,500 \mathrm{~m}, 2,000 \mathrm{~m}, 2,500 \mathrm{~m}, 3,000 \mathrm{~m}$, and 3,500 m) within a 10-day period (the average lifespan for atmospheric moisture; Trenberth et al., 2011) were selected to trace the trajectories at an acceptable accuracy. Given that HYSPLIT 4.9 may result in a disordering of water vapor trajectories, the K-means clustering 


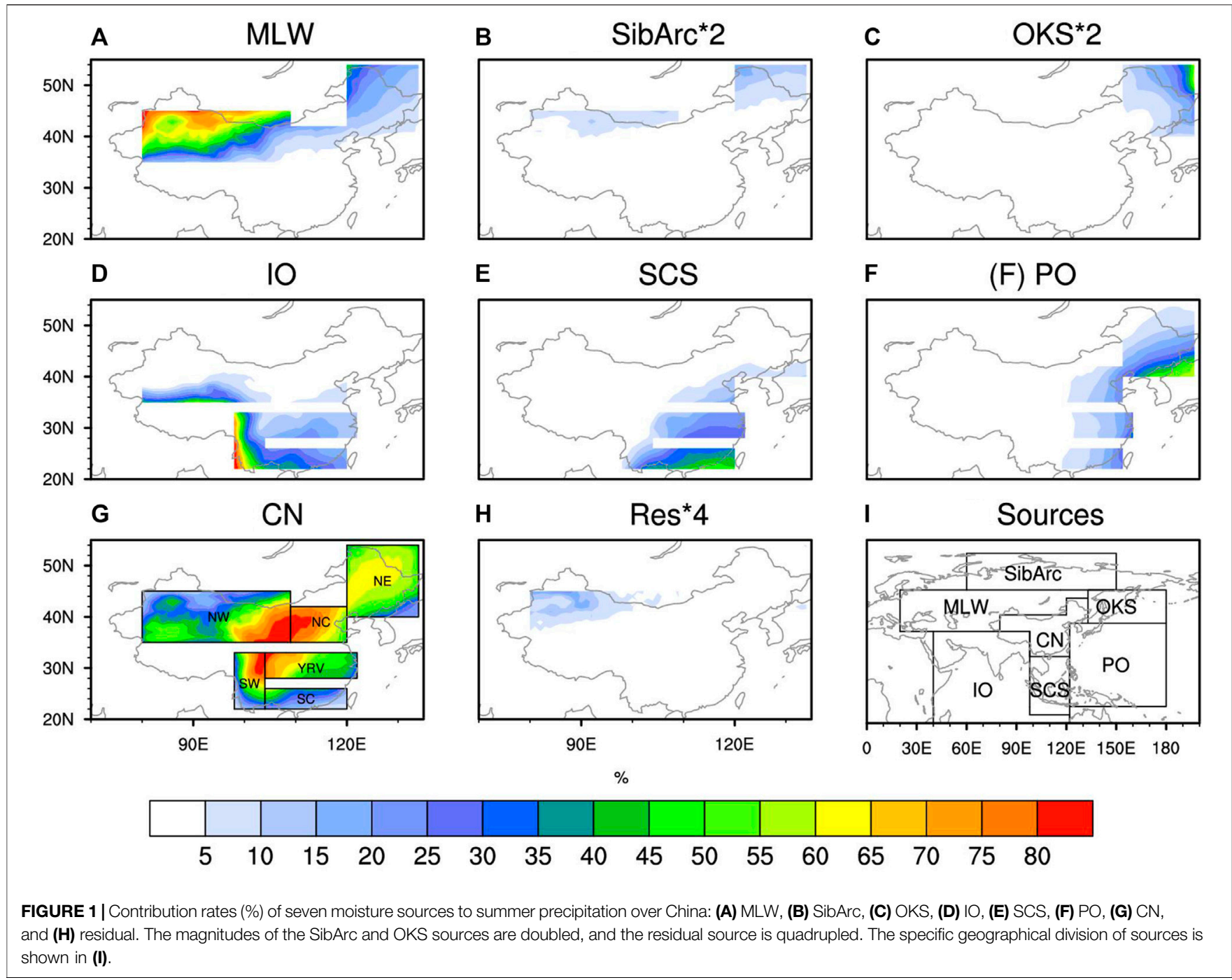

method was additionally used to cluster the trajectories (Chu et al., 2019). Several studies have expanded the usage of Lagrangian models and proposed the "moisture source attribution method (Sodemann and Stohl, 2009)" and "areal source-receptor attribution method (Sun and Wang, 2014a; Sun and Wang, 2014b)" to quantitatively compute the moisture variation along the air parcel trajectories. These methods are efficient in evaluating the relative contribution of the evaporation source to the precipitation in the target location. In this study, the air parcel trajectory and precipitation data were derived from the HYSPLIT 4.9 outputs, which were then employed to quantify the relative contributions of various moisture sources and to distinct target regions (Emil et al., 2016; Chu et al., 2019). This model also has a disadvantage in that it considers only one "evaporation (uptake)-precipitation (release)" cycle within 10 days-the mean time of one atmospheric water cycle process.

Given the complex nature of affecting regimes, we focused on seven moisture source regions in the Northern Hemisphere: the MLW, Siberian-Arctic regions (SibArc), Okhotsk Sea (OKS),
Indian Ocean (IO), South China Sea (SCS), Pacific Ocean (PO), and China Mainland $(\mathrm{CN})$. The residual sources are labeled as Res, as shown in Figure 1. Thereinto, it should be noted that the water vapor carried over the South China Sea and China Mainland were calculated independently because of their influence by several moisture transport branches. In addition, six target subregions in China were selected to provide a complete picture for China as a whole: Northwest China (NW), North China (NC), Northeast China (NE), Yangtze River Valley (YRV), South China (SC), and Southwest China (SW).

To further identify the critical atmospheric patterns that affect the variations of subregional precipitation, a series of atmospheric pattern indices were defined. The metrics are shown below:

1) The Pacific-Japan (PJ) teleconnection is a dominant pattern in the Northwest Pacific and East Asian region that features an anomalous dipole of lower tropospheric circulation over the Philippine Sea and the midlatitudes around Japan (Nitta, 1987). Conventionally, the PJ index is calculated from the leading mode of $850-\mathrm{hPa}$ vorticity over the Northwest Pacific 
$\left[10^{\circ}-55^{\circ} \mathrm{N}, 100^{\circ}-160^{\circ} \mathrm{E}\right.$ (Kosaka and Nakamura, 2010)]. In this study, we defined the PJ index with a pointwise method: $\mathrm{Z}$ $\left(45^{\circ} \mathrm{N}, 140^{\circ} \mathrm{E}\right)-\mathrm{Z}\left(20^{\circ} \mathrm{N}, 140^{\circ} \mathrm{E}\right)-\mathrm{Z}\left(60^{\circ} \mathrm{N}, 140^{\circ} \mathrm{E}\right)$, where $\mathrm{Z}$ denotes the $500-\mathrm{hPa}$ geopotential height. This PJ index is highly correlated with the classical one, with a correlation coefficient of 0.61 , suggesting its representativeness of the classical PJ pattern.

2) The East Atlantic/West Russia pattern is a prominent teleconnection pattern that affects the Eurasian climate and characterized by positive height anomalies over Europe and northern China and negative anomalies over the central North Atlantic and north of the Caspian Sea (Barnston and Livezey, 1987). Here, we defined a high-latitude Eurasian wave train index as $\mathrm{Z}\left(60^{\circ} \mathrm{N}, 75^{\circ} \mathrm{E}\right)-\mathrm{Z}\left(60^{\circ} \mathrm{N}, 30^{\circ} \mathrm{E}\right)-\mathrm{Z}\left(40^{\circ} \mathrm{N}, 135^{\circ} \mathrm{E}\right)$, and a midlatitude Eurasian wave train index as $Z\left(60^{\circ} \mathrm{N}, 50^{\circ} \mathrm{E}\right)-\mathrm{Z}$ $\left(40^{\circ} \mathrm{N}, 75^{\circ} \mathrm{E}\right)+\mathrm{Z}\left(30^{\circ} \mathrm{N}, 110^{\circ} \mathrm{E}\right)$, where $\mathrm{Z}$ again denotes the 500 $\mathrm{hPa}$ geopotential height. The correlation coefficients between the East Atlantic/West Russia index and high- and midlatitude Eurasian wave train indices are -0.12 and -0.65 , respectively, suggesting a similarity between the East Atlantic/West Russia pattern and the midlatitude Eurasian wave train pattern.

3) Following Wang et al. (2001), the WNPSH index was defined as the areal-averaged $850-\mathrm{hPa}$ geopotential height within $15^{\circ}-25^{\circ} \mathrm{N}$ and $115^{\circ}-150^{\circ} \mathrm{E}$.

4) Following Wang and Fan (1999), the ISM index was defined as the areal-averaged $850-\mathrm{hPa}$ zonal wind between $\left(5^{\circ}-15^{\circ} \mathrm{N}\right.$, $\left.40^{\circ}-80^{\circ} \mathrm{E}\right)$ and $\left(20^{\circ}-30^{\circ} \mathrm{N}, 70^{\circ}-90^{\circ} \mathrm{E}\right)$ - the former minus the latter.

5) A Northeast China Vortex index was defined as the areaaveraged $500-\mathrm{hPa}$ geopotential height over $40^{\circ}-50^{\circ} \mathrm{N}$ and $110^{\circ}-130^{\circ} \mathrm{E}$.

\section{RESULTS}

\section{Relative Contributions of the Seven Moisture Sources}

Figure 1 shows the relative contribution rates of the seven moisture sources to the climatological summer precipitation over China. The results are then further summarized in Figure 2 as a pie chart. In addition, the moisture trajectories of air parcels $10(8,6,4$, and 2) days before reaching each subregion is presented in Figure 3. It should be noted that a fair amount of the air parcels move at high latitudes, whereas the evaporation and release of moisture are mainly cycled at relatively lower latitudes. Broadly speaking, most air parcels arriving in the three northern subregions (i.e., Northwest, North and Northeast China) originate from the CN, MLW, SibArc and OKS sources, whereas air parcels that arrive in the southern subregions (i.e., Southwest, South and Southeast China) are governed predominantly by the tropical ocean and $\mathrm{CN}$ sources. Specifically, the precipitation center of the MLW source is located in Northwest and Northeast China, with area-averaged contribution rates of approximately 29.4 and $14.4 \%$, respectively (Figures 1A, 2A,C). The precipitation of the SibArc and OKS sources contributes little to summertime precipitation over the whole of China (around 1-7\%), and the target region is spatially confined to Northwest and Northeast China, which is located in the vicinity of the source origins (Figures 1B,C). The moisture trajectory of the MLW, SibArc and OKS sources can also be seen from the evolution of air parcel locations 10-2 days before reaching Northwest and Northeast China (Figures 3A,C). Regarding the tropical ocean sources, the IO source precipitation plays a decisive role in the precipitation of southwestern China (48.4\%), with the magnitude then decreasing northeastward radically from Southwest to Northwest China, the YRV, and South China (Figures 1D, 2A,C-E, 3D-F). The SCS and PO sources precipitations have similar impacts on East China (Figures 1E,F, 3D-F). The main difference is that the former makes a more prominent contribution to the precipitation of South China, with the contribution rate decreasing with latitude (Figures 1E, 2F, 3F), while the latter mainly affects the precipitation of Northeast China and the contribution rate weakens westwards from coastal to inland regions (Figures 1, 2C, 3D-F).

In addition to the six remote sources, most air parcels arriving in China are primarily dominated by the local $\mathrm{CN}$ source (Figures 1G, 2, 3). Notably, considering the local evaporation, the contribution rates of the $\mathrm{CN}$ source precipitation differ considerably among the different regions-roughly between 25.8 and $68.3 \%$. The center of China, including the North-Northwest China, YRV and Southwest China subregions, is overwhelmingly influenced by moisture transport from surrounding areas $(\sim 80 \%)$, which arguably reflects the strong feedback of local evaporation. This finding is consistent with those of Numaguti (1999) and Sun and Wang (2014b), who attributed continental evaporation as the primary origin for continental precipitation. Technically, the contribution of the $\mathrm{CN}$ source appears to be overestimated, partially due to the 10 -day tracing method, which considered only one process of evaporated moisture uptake, transport and release and therefore omitted any distant transport beyond 10 days. To sum up, these seven sources cumulatively account for greater than $95 \%$ of the total summertime precipitation, which may provide valuable precursors for synoptic-scale rainfall forecasts. The remaining contributions will come from residual sources across the globe, especially for the precipitation of Northwest China (Figure 1H).

Figure 4 shows the variations of total precipitation and relevant sources of precipitation in the different subregions of China. For each subregion, summertime precipitation shows distinct interdecadal and interannual variations. Broadly speaking, the interannual components of precipitation explain larger amounts of the total variance than the interdecadal components (Table 1). The precipitation of Northwest China and its CN source display a similar increasing trend from 1979, superimposed with clear interannual variations (Figure 4A), and their correlation coefficient is high at 0.92 (Table 2). Their interdecadal components explain approximately $18 \%$ of the total variance, with the remaining $82 \%$ from interannual timescales. The MLW and IO sources (i.e., the 2 nd and $3 \mathrm{rd}$ ) show clear interannual variations, accounting for 88 and $97 \%$ of the total variance, respectively. In comparison, the summertime precipitation in North-Northeast China, the YRV, and South 


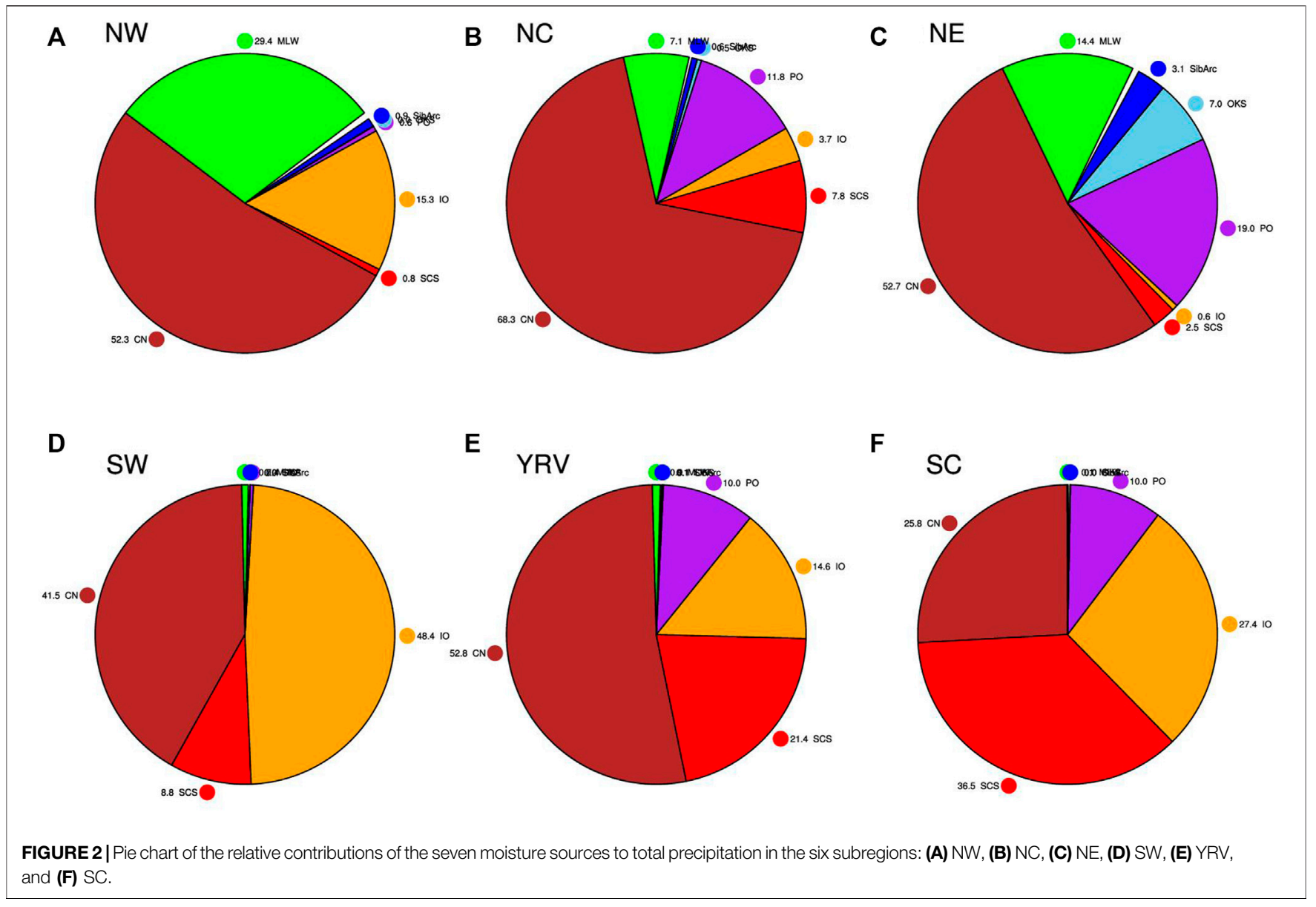

China show similar interdecadal variations superimposed with interannual variation, which is characterized by a consecutively southward retreat of summertime precipitation on interdecadal timescales (Figures 4B-E). In particular, the interdecadal component of YRV precipitation accounts for $44 \%$ of the total variance. Specifically, there is increased rainfall in Northeast China peaking in the mid-1980s, a southward displacement to North China peaking in the early 1990s, a rapid southward shift to the middle and lower YRV peaking at 1998, and then a further extension to South China peaking in the early 2000s. The decadal evolution of rain belts is consistent with the findings of previous studies (Ding et al., 2009; Zhu et al., 2011; Chu et al., 2019), which reported similar features in terms of a southward retreat. One common trait they share is the crucial role of moisture from the $\mathrm{CN}$ source in terms of total precipitation. For North China, around $68.3 \%$ of the total precipitation is determined by the $\mathrm{CN}$ moisture source, while $11.8 \%$ is determined by the PO moisture source (Figures 2B, 3B). Similarly, the $\mathrm{CN}$ and $\mathrm{PO}$ moisture transport pathways account for 52.7 and $19 \%$ of the rainfall in Northeast China, respectively, and show noticeable interdecadal variations (explained variances of 24 and $12 \%$, respectively), whilst the MLW moisture transport pathway displays evident interannual variability (explained variance of $86 \%)$. For the YRV and South China, the SCS moisture source plays a secondary and a dominant role in total rainfall, respectively, featuring similar interdecadal variations with an explained total variance of roughly $46 \%$. In addition, the IO source makes interdecadal contributions to the rainfall in the YRV and South China (explained variance of 29 and 22\%, respectively), and the PO source makes interannual contributions (93 and 99\%, respectively). As for Southwest China, the interdecadal change in precipitation is distinct from the other subregions, being characterized by decreasing rainfall from 1979 and increasing rainfall since the early 2000s, and the explained variance of the interdecadal component is $15 \%$ (Figure 4F). Almost identical interdecadal changes are found for the SCS source, with an explained variance of 19\%, whilst similar interannual variations exist for the $\mathrm{CN}$ and IO sources, both with an explained variance of $95 \%$. These results suggest that the variations of summertime precipitation differ among the six subregions of China, which is fundamentally due to the significant variations in moistures source and their relative contributions.

\section{Role of Large-Scale Atmospheric Circulation}

To better understand the causes and mechanisms involved in the variations of summertime precipitation in China, we analyzed the large-scale atmospheric circulation anomalies associated with the 


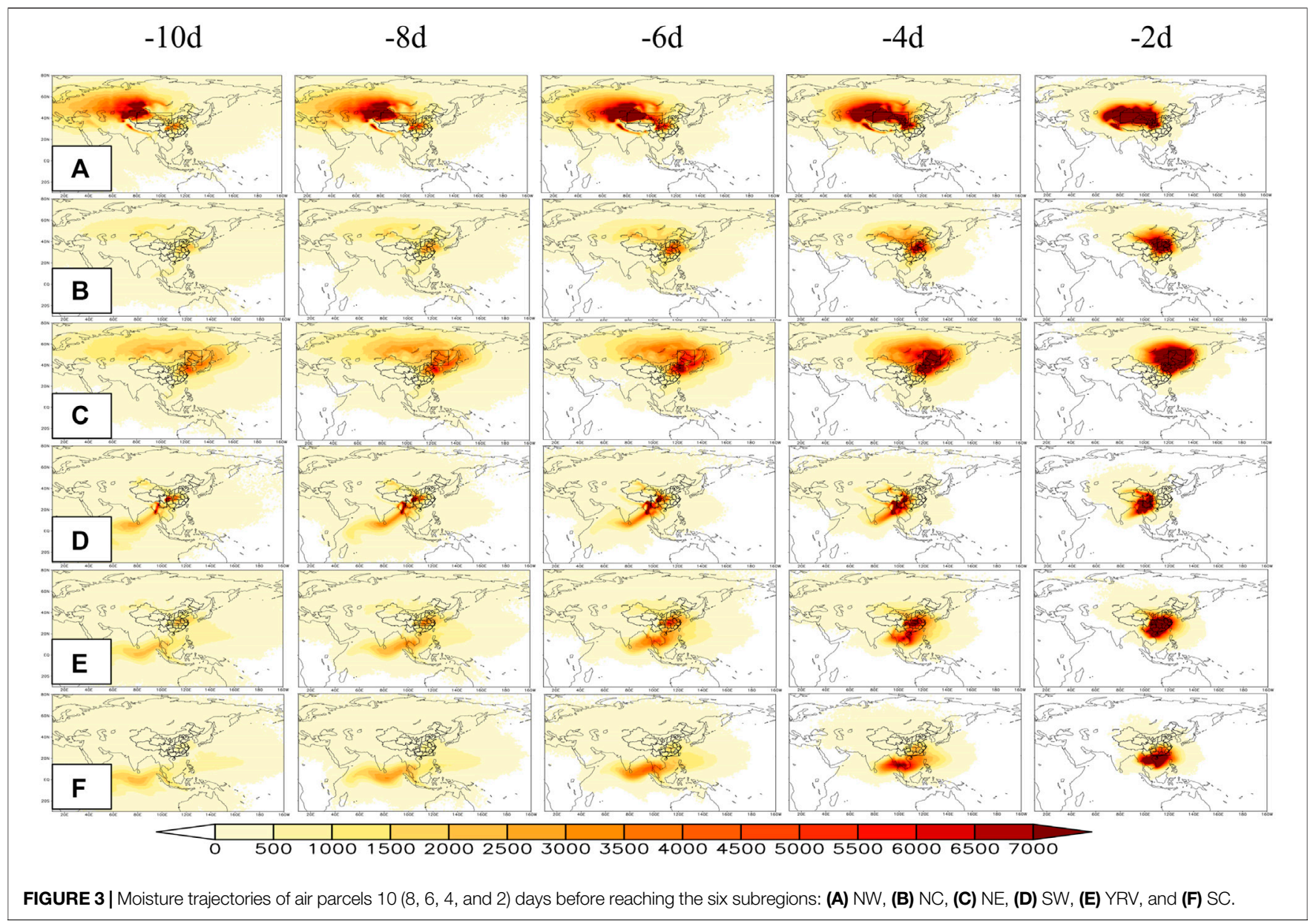

moisture sources. The key circulation patterns were identified to investigate their impacts on summertime precipitation in the different subregions. Figures 5-10 show the water vapor flux anomalies accumulated in the lower-middle troposphere and $500-\mathrm{hPa}$ geopotential height anomalies regressed on the precipitation source, and the correlation of the precipitation source anomalies with the key atmospheric circulation pattern indices.

For Northwest China (Figure 5), the CN, MLW, IO and SibArc sources are the four leading ones, accounting for 52.3, $29.4,15.3$ and $0.9 \%$ of the total precipitation, respectively. The circulation pattern associated with the MLW source shows an evident Eurasian wave train, with anomalously high pressure over a region covering Siberia to the Kara Sea and anomalously low pressure over the regions of North Europe and North Asia to Japan (Figure 5B). Such a high-latitude wave train is also apparent in the circulation pattern associated with the SibArc source (Figure 5D). Note that the circulation anomalies over the region from the Arctic to the North Atlantic project largely to the negative phase of the North Atlantic Oscillation, consistent with Hua et al. (2017). However, for the CN source, there is a fairly weak high-latitude wave train pattern over the Eurasian continent, and the circulation anomalies over China are insignificant (Figure 5A), suggesting an important contribution from local evapotranspiration. For the IO source, a similar but slightly southward-shifted wave train is identifiable over the midlatitudes extending from Europe to China and resembling the East Atlantic/West Russia pattern. Meanwhile, enhanced easterly winds are apparent over the northern India, representing an enhanced ISM (Figure 5C). Here, we define a high-latitude and a midlatitude wave train index, as described in Data and Methods. The commonality of the high-latitude and midlatitude wave trains is the cyclonic anomaly over northern China and the anticyclonic anomaly over southern China associated with the enhanced ISM. The cyclonic circulation anomaly facilitates cold-air outbreaks from high latitudes, and the anticyclonic tropospheric anomaly favors moisture transport from the tropical oceans. Therefore, the northwesterly and southwesterly branches of moisture pathways converge in Northwest China, resulting in excessive precipitation over northern and southern Northwest China, respectively (Figures 5E-H).

For North China (Figure 6), the CN, PO, MLW and SCS sources tend to be the major contributors, with contribution rates of $66.3,11.8,7.8$ and $7.1 \%$, respectively. The critical role of the $\mathrm{CN}$ source is in agreement with previous studies reporting that evaporation from the land area over and south of North China is the most important contributor (around 61.1\%) to 


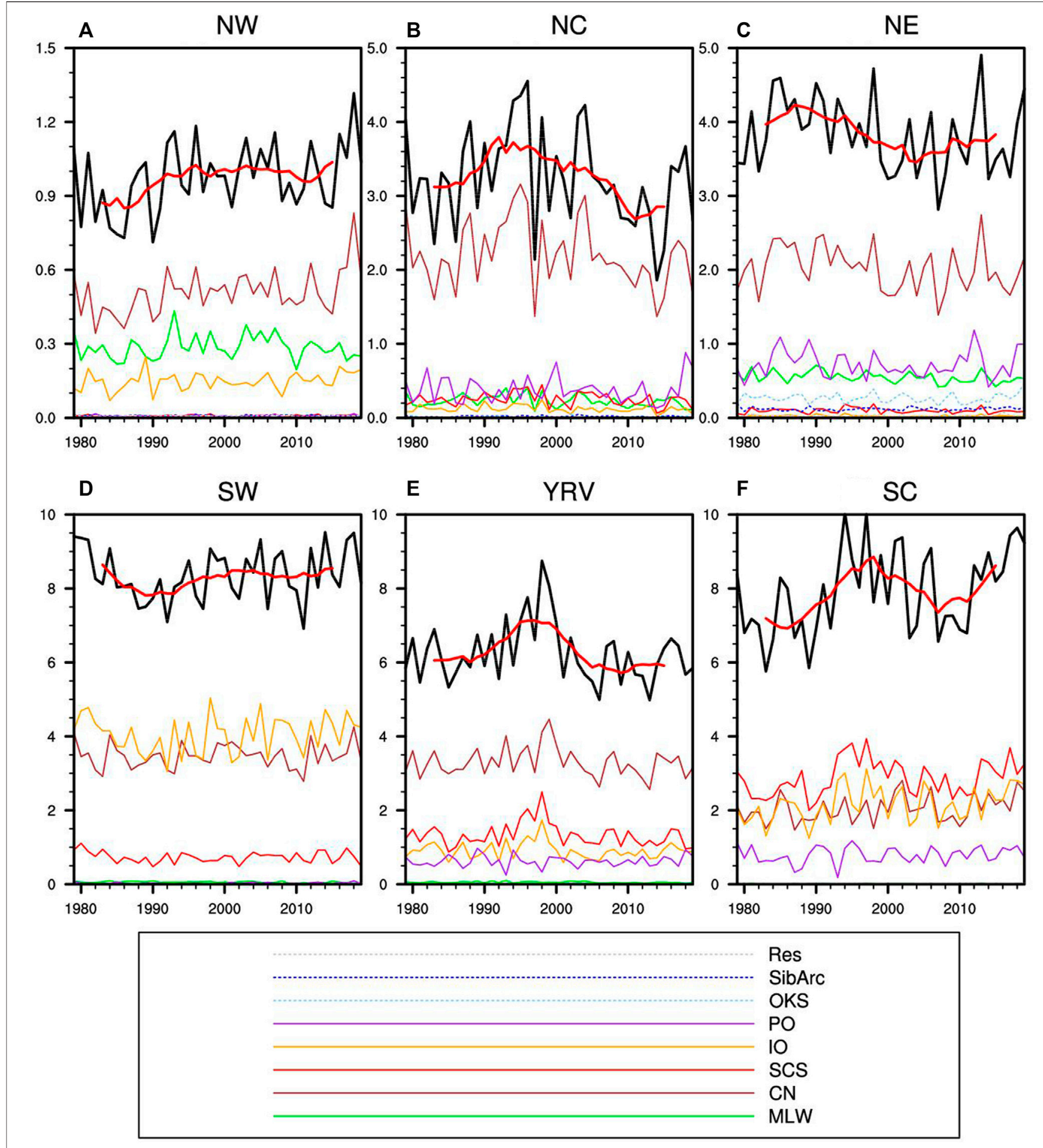

FIGURE 4 | Total precipitation (black) and the related seven moisture sources precipitation (colors) (units: $\mathrm{mm} /$ day) area-averaged over the six subregions: (A) NW, (B) NC, (C) NE, (D) SW, (E) YRV, and (F) SC. The thick red lines overlaid on the black lines denote the 9-year running average of the total precipitation. The green, brown, red, orange, purple, sky-blue, blue and gray lines denote the MLW, CN, SCS, IO, PO, OKS, SibArc and Res sources, respectively.

the summertime rainfall in North China (Sun and Wang, 2014; Chu et al., 2019). The circulation patterns related to the $\mathrm{CN}$ and MLW sources are a similar high-latitude wave train, and the anomalously low center over Northeast China will certainly lead to a uniform increase in summertime precipitation over North China (Figures 6A,C). In particular, the MLW source gives rise to 
TABLE 1 | Explained variances of summertime total and source precipitation in different regions by the interannual and interdecadal component.

\begin{tabular}{|c|c|c|c|c|c|c|c|c|c|c|c|c|}
\hline & \multicolumn{6}{|c|}{ Interannual component } & \multicolumn{6}{|c|}{ Interdecadal component } \\
\hline & NW & NC & NE & YRV & SC & sw & NW & NC & NE & YRV & SC & sw \\
\hline Total & $82 \%$ & $68 \%$ & $76 \%$ & $56 \%$ & $66 \%$ & $85 \%$ & $18 \%$ & $32 \%$ & $24 \%$ & $44 \%$ & $34 \%$ & $15 \%$ \\
\hline MLW & $88 \%$ & $90 \%$ & $86 \%$ & $77 \%$ & $95 \%$ & $77 \%$ & $12 \%$ & $10 \%$ & $14 \%$ & $23 \%$ & $5 \%$ & $23 \%$ \\
\hline $\mathrm{CN}$ & $83 \%$ & $71 \%$ & $76 \%$ & $75 \%$ & $89 \%$ & $95 \%$ & $17 \%$ & $29 \%$ & $24 \%$ & $25 \%$ & $11 \%$ & $5 \%$ \\
\hline SCS & $91 \%$ & $80 \%$ & $82 \%$ & $54 \%$ & $54 \%$ & $81 \%$ & $9 \%$ & $20 \%$ & $18 \%$ & $46 \%$ & $46 \%$ & $19 \%$ \\
\hline 10 & $97 \%$ & $86 \%$ & $81 \%$ & $71 \%$ & $78 \%$ & $95 \%$ & $3 \%$ & $14 \%$ & $19 \%$ & $29 \%$ & $22 \%$ & $5 \%$ \\
\hline PO & $99 \%$ & $91 \%$ & $88 \%$ & $93 \%$ & $99 \%$ & $98 \%$ & $1 \%$ & $9 \%$ & $12 \%$ & $7 \%$ & $1 \%$ & $2 \%$ \\
\hline OKS & $84 \%$ & $89 \%$ & $98 \%$ & $94 \%$ & $84 \%$ & $83 \%$ & $16 \%$ & $11 \%$ & $2 \%$ & $6 \%$ & $16 \%$ & $17 \%$ \\
\hline SibArc & $97 \%$ & $91 \%$ & $99 \%$ & $91 \%$ & $90 \%$ & $96 \%$ & $3 \%$ & $9 \%$ & $1 \%$ & $9 \%$ & $10 \%$ & $4 \%$ \\
\hline
\end{tabular}

TABLE 2 | Correlation coefficients between total precipitation and related source precipitation in different subregions. Asterisks denote correlation coefficients exceeding the $95 \%$ confidence level.

\begin{tabular}{lcccccc} 
& NW & NC & NE & YRV & SC & SW \\
\hline MLW & $0.64^{\star}$ & $0.56^{\star}$ & $0.65^{\star}$ & $0.45^{\star}$ & 0.12 & -0.04 \\
$\mathrm{CN}$ & $0.92^{\star}$ & $0.97^{\star}$ & $0.92^{\star}$ & $0.90^{\star}$ & $0.76^{\star}$ & $0.62^{\star}$ \\
$\mathrm{SCS}$ & $0.53^{\star}$ & $0.71^{\star}$ & $0.48^{\star}$ & $0.89^{\star}$ & $0.80^{\star}$ & $0.41^{\star}$ \\
$\mathrm{IO}$ & $0.55^{\star}$ & $0.61^{\star}$ & $0.38^{\star}$ & $0.84^{\star}$ & $0.88^{\star}$ & $0.83^{\star}$ \\
$\mathrm{PO}$ & $0.46^{\star}$ & $0.37^{\star}$ & $0.63^{\star}$ & -0.27 & 0.24 & 0.20 \\
OKS & 0.22 & 0.06 & $0.39^{\star}$ & 0.24 & -0.16 & -0.05 \\
SibArc & $0.38^{\star}$ & $0.53^{\star}$ & -0.06 & 0.15 & 0.02 & -0.18
\end{tabular}

a rainfall belt across North China (Figure 6G). Besides the $\mathrm{CN}$ source, the PO is the most significant source of moisture and dynamics for precipitation in North China. An apparent meridional wave train that closely resembles the positive phase of the PJ teleconnection pattern acts as an atmospheric bridge linking the PO moisture source to rainfall in North China, accompanied by cyclonic (anticyclonic) anomalies in the tropical (midlatitude) Northwest Pacific (Figure 6B). Such anomalously strong convective activity over the tropics tends to the promotion of a Rossby wave teleconnection in the poleward direction (Kosaka and Nakamura, 2010). The East Asian-western North Pacific monsoon (Wang et al., 2008) provides an additional source of moisture from the PO for the abundant rainfall over eastern North China (figure not shown). In addition, the SCS source is associated with an enhanced WNPSH, which brings abundant water vapor along the western margin of the subtropical high (Figure 6D). This finding is consistent with those of Ding et al. (2009) and Jiang et al. (2017) who reported that the southwesterly moisture transport associated with the PO and SCS sources is the dominant moisture pathway for variations of North China precipitation. In summary, the mid-high-latitude wave train, subtropical high, and PJ teleconnection are dominant circulation systems for North China precipitation.

Figure 7 shows the major circulation patterns that govern the variations of Northeast China precipitation. The CN, PO, MLW and OKS sources explain 52.7, 19, 14.4 and $7 \%$ of total rainfall, respectively. A common feature for the circulation anomalies is the prominent cyclonic anomaly over Northeast China, which can be regarded as the Northeast China vortex-the classic climate system affecting northern China. This pattern is especially evident in the circulation patterns associated with the CN, MLW and OKS sources (Figures $7 \mathbf{A}, \mathbf{C}, \mathbf{D}$ ). It is reasonable to assume that the Northeast China vortex converges together the water vapor branches from the west (MLW source), south (CN source), and east (OKS source), and thus produces heavy rainfall over vast regions of North and Northeast China (Figures 7E,G,H). However, an anticyclonic circulation system associated with the PO source is identifiable over the Okhotsk Sea, reflecting the remote influence of the PJ teleconnection (Figure 7B). The southwesterly moisture transmission branch transports moisture from the PO along the western margin of the anticyclone and yields excessive rainfall over East China (Figure 7F). In addition, the precipitation over Northeast China might be influenced by the East Asian summer monsoon, which transports water vapor from the SCS source (Sun et al., 2017)-something that can also be seen in the OKSrelated circulation pattern (Figure 7D). To sum up, summertime precipitation in northern China, including the Northwest, North and Northeast China subregions, is primarily affected by atmospheric regimes in in mid-high-latitudes, such as mid-high-latitude wave trains, the Northeast China vortex, and the PJ teleconnection. The exception is that the subtropical high has additional impacts on North China precipitation and the ISM has extra effects on Northwest China precipitation.

Considering the complex regime of atmospheric water vapor transport over northern and southern China (Zhou and $\mathrm{Yu}$, 2005), the atmospheric sources of the southern subregions could be different from those of the northern subregions. Aside from North China, the YRV and South China subregions are significantly affected by the East Asian summer monsoon and subtropical high. Therefore, there will be intrinsic linkages among the summertime precipitation in these three subregions. For instance, the anomalously stronger East Asian summer monsoon brings excessive rainfall to North and South China and insufficient rainfall to the YRV. Such an out-of-phase relationship in rainfall is linked to the variability of the East Asian monsoon (Ding et al., 2009). Summertime precipitation in the YRV is predominantly controlled by the $\mathrm{CN}(52.8 \%)$, SCS (21.4\%), IO (14.6\%), and PO (10\%) sources, which together account for approximately $98 \%$ of total precipitation (Figure 2E). These relative contributions of moisture sources are slightly distinct from those reported by Chu et al. (2019), partly due to the different methods used for classifying water vapor sources. In the present study, the $\mathrm{CN}$ precipitation source 


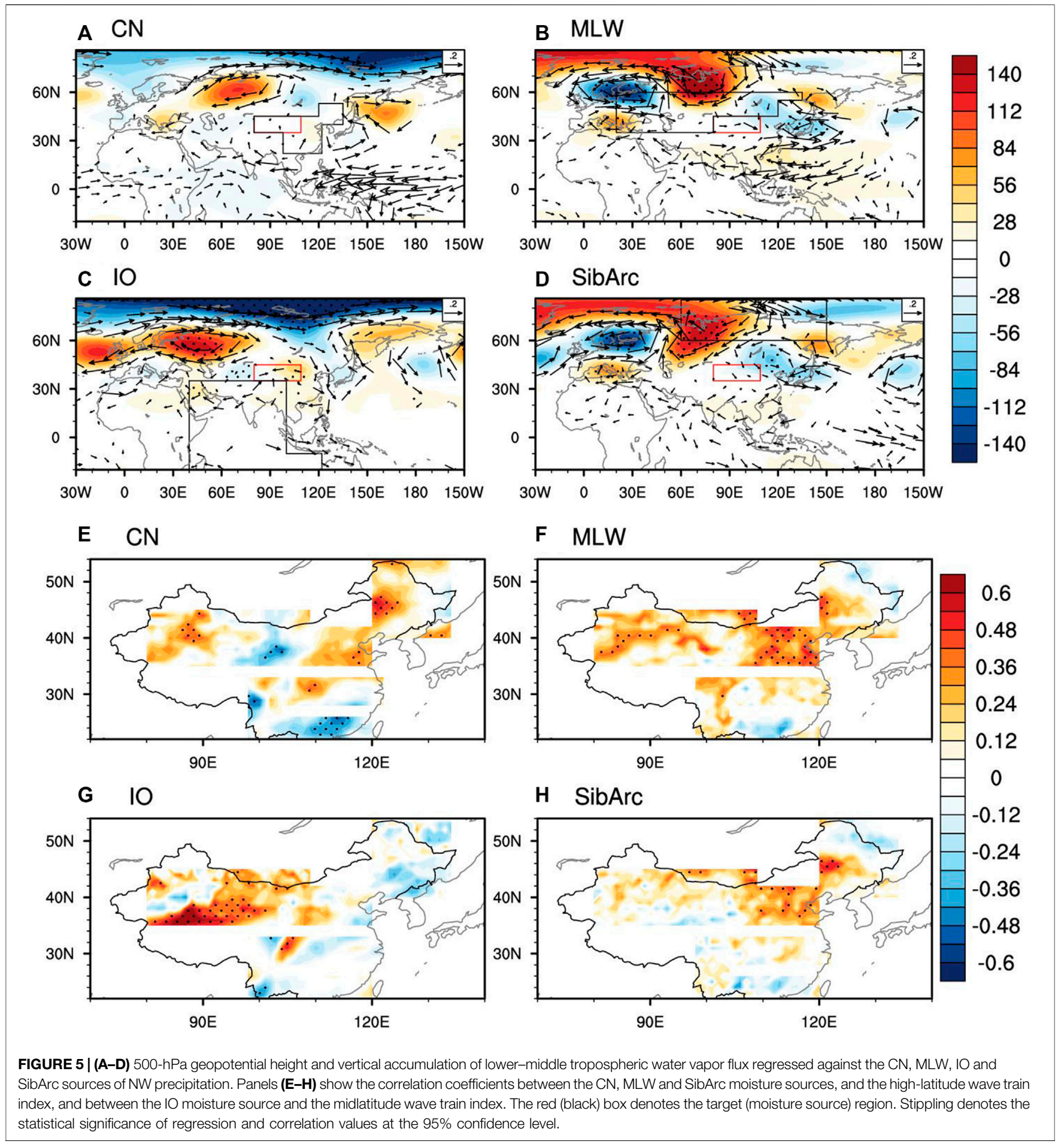

for the YRV is controlled by southwesterly and northerly moisture branches, which transport moisture from southern China and North-Northeast China, respectively (Figure 8A). This suggests that, similar to North China rainfall (Sun and Wang, 2014), the YRV rainfall largely originates from the evaporation taking place over land areas, rather than oceanic factors (Wei et al., 2012). In addition, a strengthened subtropical high, along with a weakened East Asian summer monsoon (figure not shown), is the key contributor to the southwesterly moisture pathway of YRV rainfall, which carries water vapor from the SCS and IO sources (Figures 8B,C), consistent with the findings of Fan et al. (2008) and Wang and Chen (2012). Simultaneously, a weakened ISM is apparent alongside the strengthened subtropical high (Figure 8C), which corresponds to more rainfall over the 


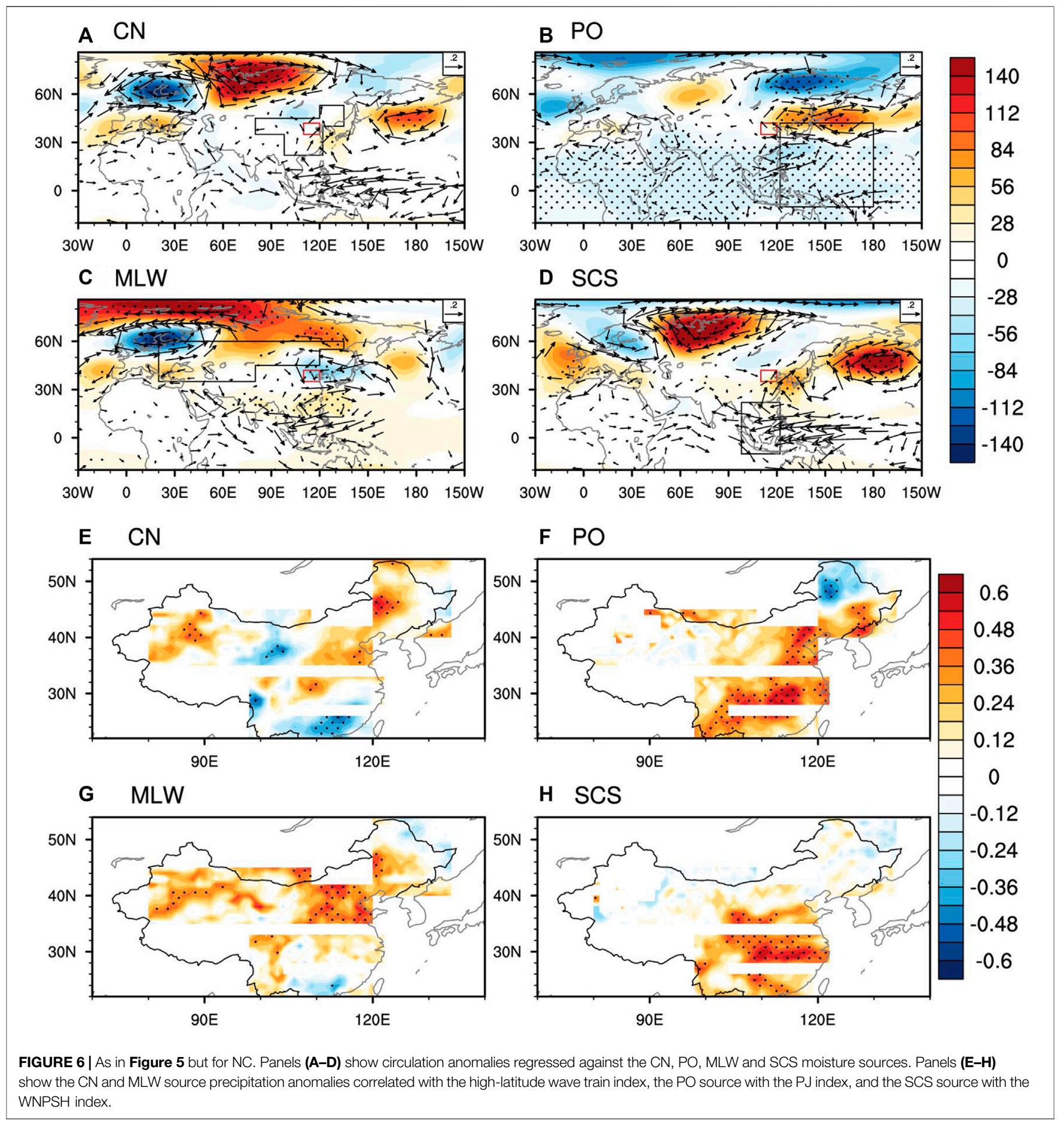

YRV, consistent with the conclusion in Zhang (2001). The PJ teleconnection appears to be closely linked with the PO precipitation source (Figures $\mathbf{8 D}, \mathbf{H}$ ). The aforementioned outof-phase relationship with total precipitation is reproduced in the $\mathrm{CN}$ and IO precipitation sources (Figures 8E,G). These results indicate that the subtropical high and PJ pattern provide uniformly excessive summertime rainfall over the whole of East China, while the evaporation from land areas and the
ISM provide additional information for the uneven distribution of East China rainfall.

In comparison, the precipitation in South China is dominated by the SCS, IO, CN and PO sources (Figure 9), with contribution rates of $36.5,27.4,25.8$ and $10 \%$, respectively. Note that $\mathrm{CN}$ is no longer the primary source for South China precipitation owing to the increased influence from the tropical oceans. Like the YRV, the precipitation in South China is affected primarily by 


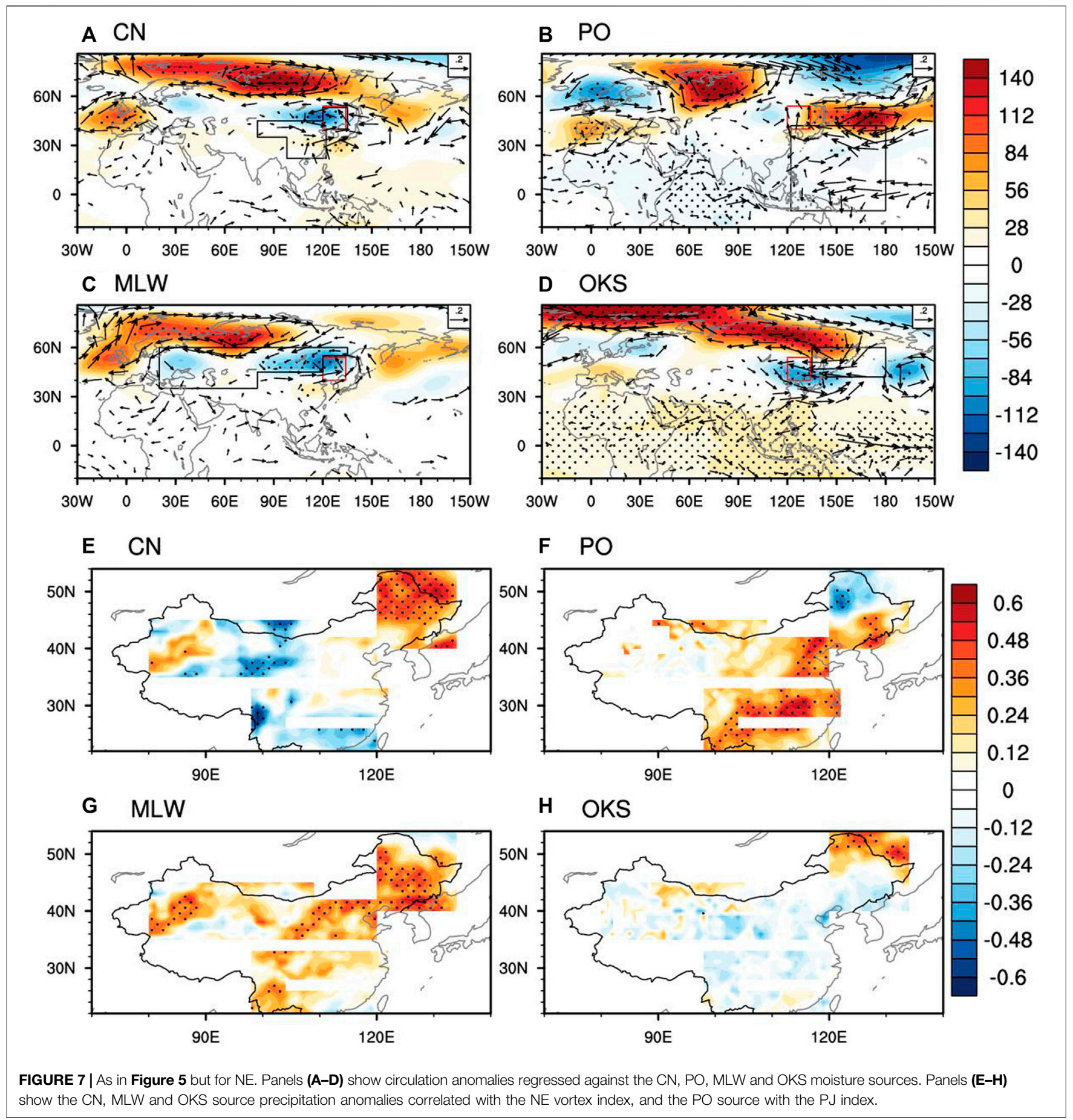

enhanced southerly winds from the SCS source, corresponding to an intensified subtropical high (Figure 9A). On the contrary, a weakened subtropical high and enhanced East Asian-western North Pacific monsoon can also bring water vapor from land evaporation over the north of South China (Figure 9C), resulting in less rainfall over the YRV and, in turn, heavy rainfall over South China (Figure 9G). In addition, a weakened ISM transports water vapor from the Indian Ocean through the westerly branch of moisture pathways over northern India
(Figure 9B), leading to excessive IO-source precipitation over western South China (Figure 9F). The PO source further causes spatially restricted rainfall over South China through the PJ teleconnection and the enhanced monsoon (Figures 9D,H). These results suggest that the moisture transport from the SCS and IO sources dominates the variation in South China precipitation (Sun and Wang, 2014; Chu et al., 2019) through a strengthened subtropical high and weakened ISM. Conversely, land evaporation from $\mathrm{CN}$ becomes less important, particularly 


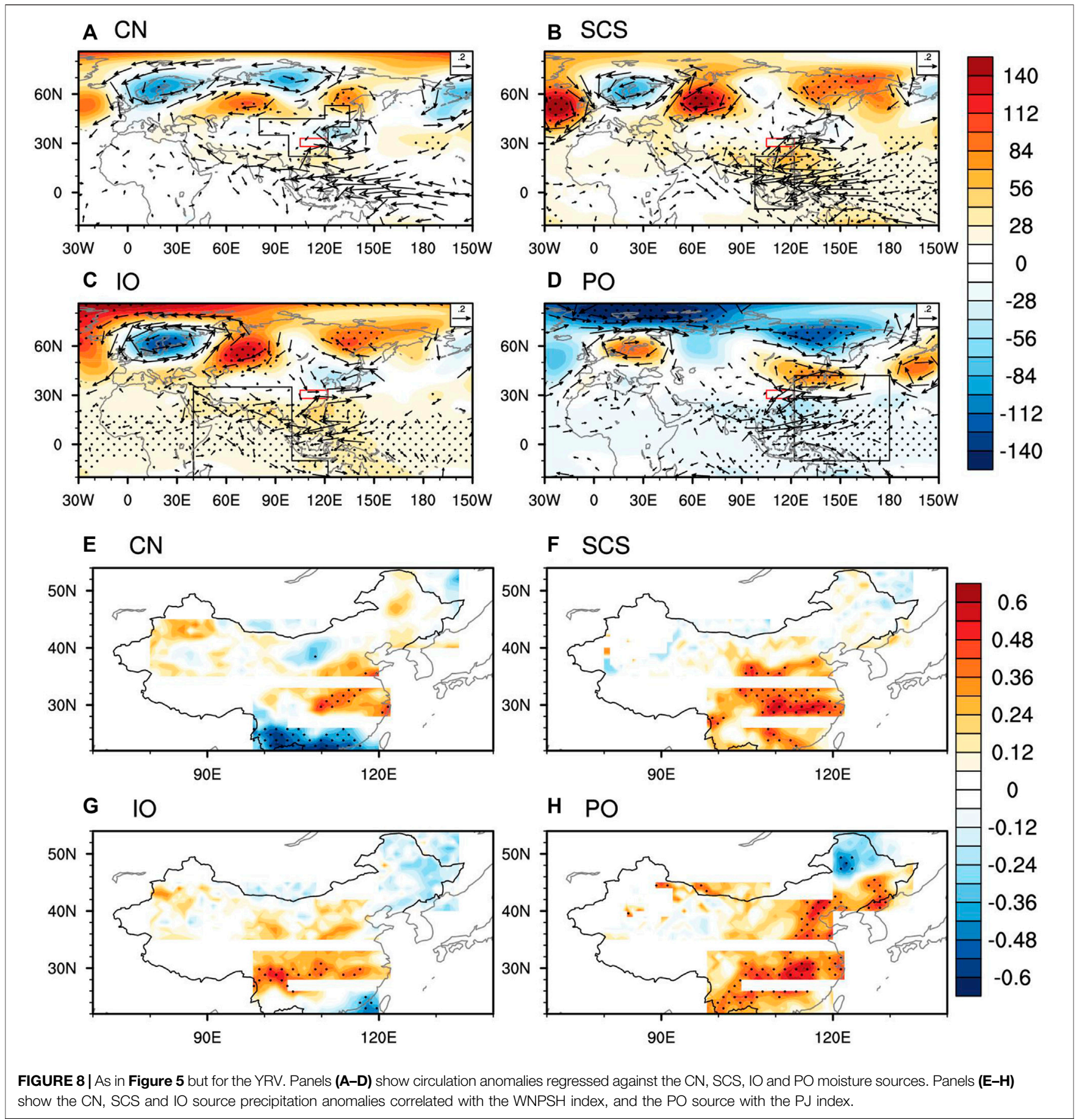

relative to YRV and North China precipitation, with moisture contributions mainly from the YRV region or the PO through a weakened subtropical high.

The relative contributions to precipitation in Southwest China are distinct from those of other subregions in that the IO (48.4\%), CN (41.5\%) and SCS (8.8\%) are the primary sources for Southwest China precipitation, which together explain $99.1 \%$ of the total precipitation (Figure 10). The amplified subtropical high, along with weakened ISM, brings water vapor from the Bay of Bengal and the Indian Ocean via a southwesterly pathway (Figure 10A). These two branches of moisture pathways result in strong convergence and hence heavy rainfall over Southwest China (Figure 10D). Similarly, the intensified subtropical high associated with the SCS source also transports moisture from the PO through the southeasterly moisture branch (Figure 10C), resulting in a belt of heavy rain 


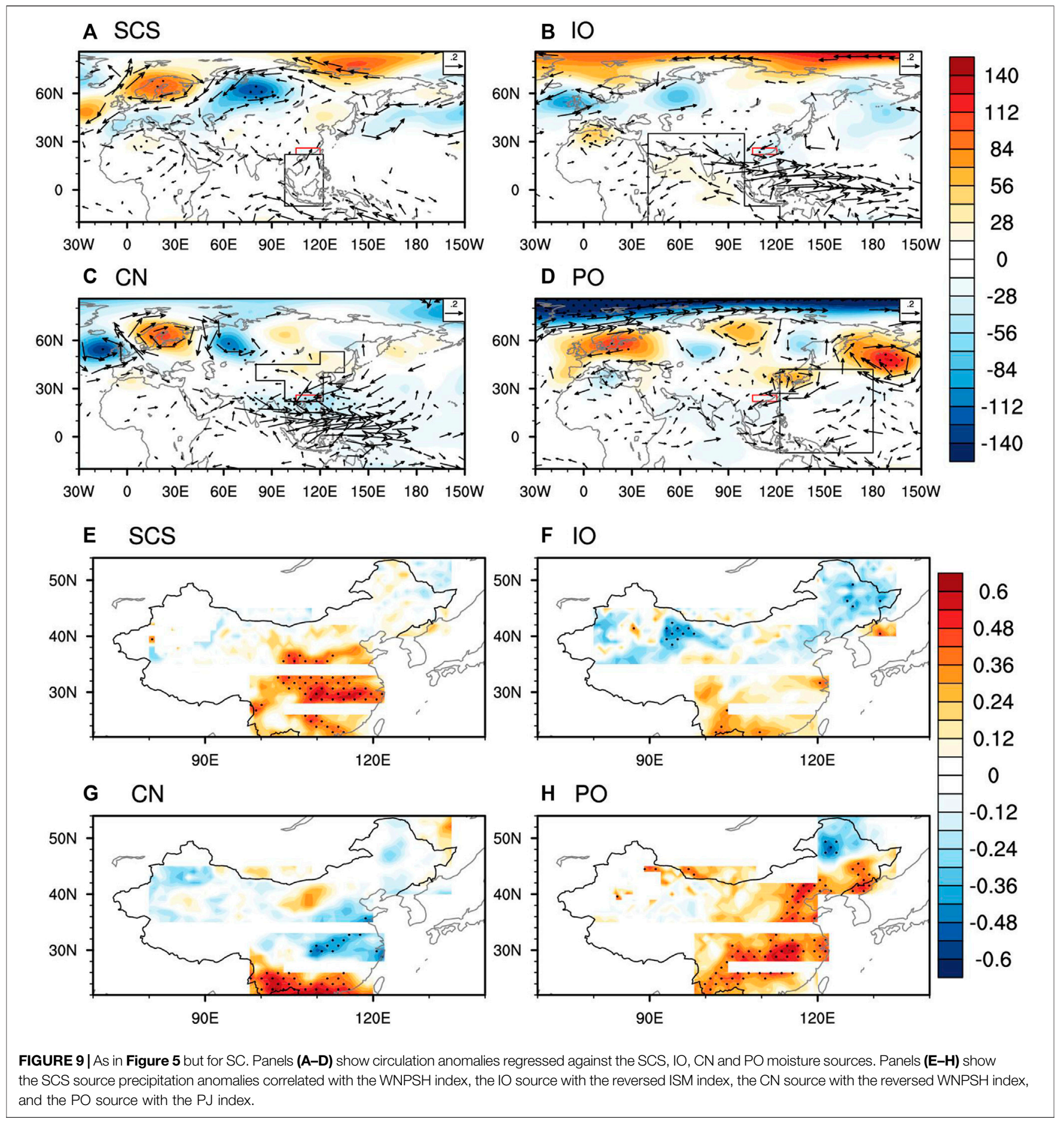

over the whole of southern China and southern North China (Figure 10F). Conversely, the $\mathrm{CN}$ source is associated with a weakened subtropical high and enhanced East Asian-Western North Pacific monsoon, albeit the pattern is more zonally orientated, with the easterly winds bringing moisture transport from the evaporation over land areas (Figure 10B). This indicates that the heavy rainfall over South China can provide further evaporation sources for Southwest China precipitation (Figure 10E). To sum up, different from northern China, the three southern China subregions are primarily controlled by atmospheric circulation regimes associated with tropical ocean origins south of the mainland, such as the subtropical high, East Asian summer monsoon, and ISM. 


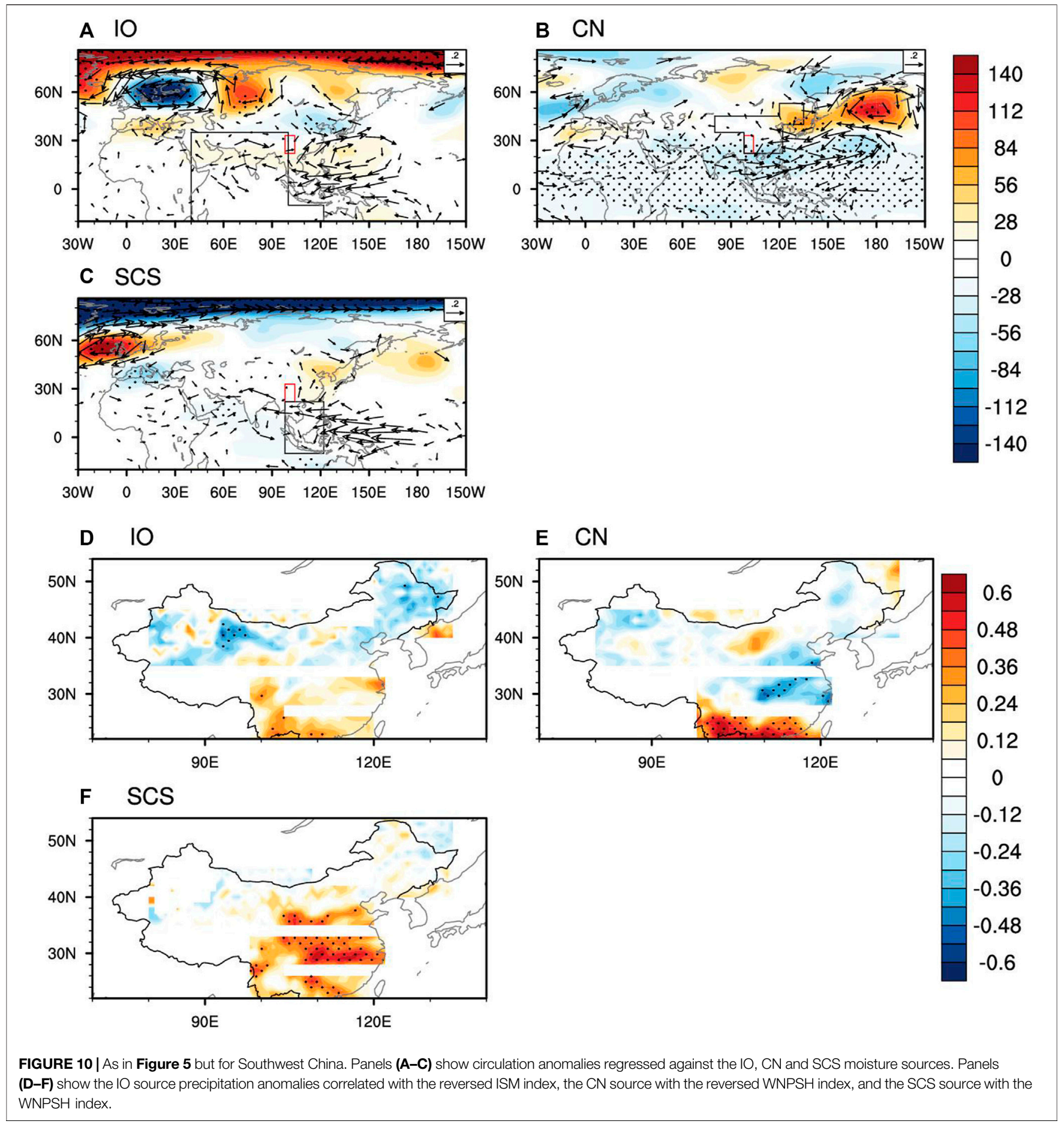

\section{CONCLUSION}

In this study, version 4.9 of the HYSPLIT model was used to quantitatively simulate the potential moisture sources (i.e., MLW, SibArc, OKS, IO, SCS, PO, and CN) and transport features for the interannual and interdecadal variation of summertime precipitation in six subregions of China. In addition, the largescale atmospheric circulation regimes and associated mechanisms for these source-receptor linkages were further analyzed. Based on the 10-day trajectories of air parcels, the relative contributions of different moisture sources were calculated. The main results can be summarized as follows:

The CN, MLW, IO and SibArc sources of precipitation account for $52.3,29.4,15.3$ and $0.9 \%$ of the precipitation in Northwest China, respectively, and thus the $\mathrm{CN}$ source dominates the increasing trend of precipitation in this region 
and the MLW and IO sources govern the interannual and interdecadal variation. Mid-high-latitude wave trains are the dominant regimes for excessive rainfall over Northwest China, via the transport of moisture from evapotranspiration in Eurasian land areas, as well as from the Arctic and the Indian Ocean.

For North China, the precipitation originating from evapotranspiration in land areas (66.3\%) is strong, in which a high-latitude wave train and the WNPSH are dynamically involved in the underlying mechanisms. The PO, MLW and SCS sources are essential for the interannual variation of summertime precipitation, with the PJ teleconnection, mid-high-latitude wave train, and East Asian summer monsoon transporting moisture via the easterly, westerly and southwesterly branches.

Likewise, precipitation originating from evapotranspiration over land areas is the key contributor to the variation in Northeast China precipitation. The Northeast China vortex, which transports water vapor from the $\mathrm{CN}$, MLW and OKS sources, is the major regime affecting the summertime climate over Northeast China. The PJ teleconnection has an additional impact through the southeasterly branch of moisture transport from the PO. Meanwhile, the contributions from the SibArc and SCS sources can not be neglected (3.1 and 2.5\%)

For the YRV, similarly, land evapotranspiration and the SCS and IO sources are the predominant moisture sources for the variation of precipitation, mainly through the southwesterly branch of moisture transport pathways via intensified subtropical high coupling with a weakened East Asian monsoon and ISM. The Asian monsoon appears to have opposite impacts on summertime precipitation over the YRV and South China subregions. Additionally, the PJ teleconnection contributes to the variation of summertime rainfall through the easterly branch of moisture transport from the PO.

The moisture sources for precipitation in South and Southwest China are distinct from those of the northern subregions, suggesting that tropical ocean sources are key contributors to precipitation in southern subregions, rather than the $\mathrm{CN}$ source. The SCS and IO sources are the major ones in terms of the interdecadal change in South China precipitation, largely due to the southerly and westerly winds associated with the subtropical high and weakened ISM. Besides, the CN source contributes to $25.8 \%$ of total rainfall, with most of the land evapotranspiration coming from the YRV region.

For Southwest China, the weakened ISM accompanying the enhanced subtropical high, associated with the IO source, leads to

\section{REFERENCES}

Barnston, A. G., and Livezey, R. E. (1987). Classification, Seasonality and Persistence of Low-Frequency Atmospheric Circulation Patterns. Mon. Wea. Rev. 115, 1083-1126. doi:10.1175/1520-0493(1987)115<1083:csapol >2.0.co;2

Chen, B., Xu, X. D., Yang, S., and Zhang, W. (2012). On the Origin and Destination of Atmospheric Moisture and Air Mass over the Tibetan Plateau. Theor. Appl. Climatol. 110, 423-435. doi:10.1007/s00704-012-0641-y

Chen, Y., and Luo, Y. (2018). Analysis of Paths and Sources of Moisture for the South China Rainfall during the Presummer Rainy Season of 1979-2014. J. Meteorol. Res. 32, 744-757. doi:10.1007/s13351-018-8069-7 the convergence of water vapor over Southwest China, resulting in excessive rainfall. The second contributor would be the $\mathrm{CN}$ source, which transports water vapor from South China through an oppositely weakened subtropical high.

The present study builds upon some already considerable advances in understanding the source-receptor relationship between moisture sources and summertime precipitation in China at the subregional scale. Thereinto, the complex, largescale circulation regimes responsible for these linkages can provide useful precursors for summertime climate prediction. Although this study offers some progress in elucidating the complexity of this topic through observational analysis and 10-day simulations with HYSPLIT 4.9, the precise physical processes and possible external forcings underpinning the variations of summertime precipitation remain to be comprehensively explored. These aspects should be addressed by analyzing numerical simulation results using state-of-art atmospheric or coupled models. Given that the HYSPLIT model considers only one "evaporation (uptake)-precipitation (release)" cycle, the analysis of multicycle processes may be necessary for future research, which will necessitate more computations and discussions.

\section{DATA AVAILABILITY STATEMENT}

The original contributions presented in the study are included in the article/Supplementary Material, further inquiries can be directed to the corresponding author.

\section{AUTHOR CONTRIBUTIONS}

RZ and QC conceived the study, and RZ wrote the manuscript. ZZ and YQ provided critical feedback and helped shape the research and manuscript. All authors contributed to the article and approved the submitted version.

\section{FUNDING}

RZ was supported by the National Key Research and Development Program of China (Grant 2016YFA0601500), the National Natural Science Foundation of China (Grant 42075016), and the Shanghai Pujiang Program (Grant 2020PJD004).

Chu, Q.-c., Zhi, R., Wang, Q.-g., and Feng, G.-l. (2019). Roles of Moisture Sources and Transport in Precipitation Variabilities during Boreal Summer over East China. Clim. Dyn. 53, 5437-5457. doi:10.1007/s00382-019-04877-z

Ding, Y., Sun, Y., Wang, Z., Zhu, Y., and Song, Y. (2009). Inter-decadal Variation of the Summer Precipitation in China and its Association with Decreasing Asian Summer Monsoon Part II: Possible Causes. Int. J. Climatol. 29 (13), 1926-1944. doi:10.1002/joc.1759

Draxler, R. R., and Hess, G. D. (1998). An Overview of the HYSPLIT_4 Modeling System of Trajectories, Dispersion, and Deposition. Aust. Meteorol. Mag. 47 (4), 295-308.

Drumond, A., Nieto, R., and Gimeno, L. (2011). Sources of Moisture for China and Their Variations during Drier and W-etter C-onditions in 2000-2004: a Lagrangian A-pproach. Clim. Res. 50, 215-225. doi:10.3354/cr01043 
Emil, S. D., Amey, P., and Subimal, G. (2016). Use of Atmospheric Budget to Reduce Uncertainty in Estimated Water Availability over South Asia from Different Reanalyses. Sci. Rep. 6, 29664. doi:10.1038/srep29664

Fan, K., Wang, H., and Choi, Y. J. (2008). A Physically-Based Statistical Forecast Model for the Middle-Lower Reaches of the Yangtze River Valley Summer Rainfall. Chin. Sci. Bull. 53, 602-609. doi:10.1007/s11434-008-0083-1

Gimeno, L., Drumond, A., Nieto, R., Trigo, R. M., and Stohl, A. (2010). On the Origin of continental Precipitation. Geophys. Res. Lett. 37, L13804. doi:10.1029/ $2010 \mathrm{gl} 043712$

Gong, D. Y., Wang, S. W., and Zhu, J. H. (2001). East Asian winter Monsoon and Arctic Oscillation. Geophys. Res. Lett. 28, 2073-2076. doi:10.1029/ 2000GL012311

Hua, L., Zhong, L., and Ma, Z. (2017). Decadal Transition of Moisture Sources and Transport in Northwestern China during Summer from 1982 to 2010. J. Geophys. Res. Atmos. 122, 12522-12540. doi:10.1002/2017jd027728

Huang, G., Liu, Y., and Huang, R. (2011). The Interannual Variability of Summer Rainfall in the Arid and Semiarid Regions of Northern China and its Association with the Northern Hemisphere Circumglobal Teleconnection. Adv. Atmos. Sci. 28, 257-268. doi:10.1007/s00376-010-9225-x

Jiang, Z. H., Ren, W., Liu, Z. Y., and Yang, H. (2013). Analysis of Water Vapor Transport Characteristics During the Meiyu over the Yangtze Huaihe River Valley using the Lagrangian Method. Acta. Meteorol. Sci. 71 (2), 295-304 (in Chinese).

Jiang, Z., Jiang, S., Shi, Y., Liu, Z., Li, W., and Li, L. (2017). Impact of Moisture Source Variation on Decadal-Scale Changes of Precipitation in North China from 1951 to 2010. J. Geophys. Res. Atmos. 122, 600-613. doi:10.1002/ 2016jd025795

Kosaka, Y., and Nakamura, H. (2010). Mechanisms of Meridional Teleconnection Observed between a Summer Monsoon System and a Subtropical Anticyclone. Part I: The Pacific-Japan Pattern. J. Clim. 23, 5085-5108. doi:10.1175/ 2010jcli3413.1

Li, F., and Wang, H. (2013). Autumn Sea Ice Cover, winter Northern Hemisphere Annular Mode, and winter Precipitation in Eurasia. J. Clim. 26, 3968-3981. doi:10.1175/jcli-d-12-00380.1

Liu, J., Curry, J. A., Wang, H., Song, M., and Horton, R. M. (2012). Impact of Declining Arctic Sea Ice on winter Snowfall. Proc. Natl. Acad. Sci. 109, 4074-4079. doi:10.1073/pnas.1114910109

Nitta, T. (1987). Convective Activities in the Tropical Western Pacific and Their Impact on the Northern Hemisphere Summer Circulation. J. Meteorol. Soc. Jpn. 65, 373-390. doi:10.2151/jmsj1965.65.3_373

Numaguti, A. (1999). Origin and Recycling Processes of Precipitating Water over the Eurasian Continent: Experiments Using an Atmospheric General Circulation Model. J. Geophys. Res. 104, 1957-1972. doi:10.1029/1998jd200026

Renhe, Z. (2001). Relations of Water Vapor Transport from Indian Monsoon with that over East Asia and the Summer Rainfall in China. Adv. Atmos. Sci. 18, 1005-1017. doi:10.1007/BF03403519

Simmonds, I., Bi, D., and Hope, P. (1999). Atmospheric Water Vapor Flux and its Association with Rainfall overChina in Summer. J. Clim. 12, 1353-1367. doi:10.1175/1520-0442(1999)012<1353:awvfai >2.0.co;2

Sodemann, H., and Stohl, A. (2009). Asymmetries in the Moisture Origin of Antarctic Precipitation. Geophys. Res. Lett. 36, L22803. doi:10.1029/ $2009 \mathrm{gl} 040242$

Stohl, A., and James, P. (2005). A Lagrangian Analysis of the Atmospheric Branch of the Global Water Cycle. Part II: Moisture Transports between Earth's Ocean Basins and River Catchments. J. Hydrometeorol. 6, 961-984. doi:10.1175/ Jhm 470.1

Sun, B., and Wang, H. (2014b). Analysis of the Major Atmospheric Moisture Sources Affecting Three Sub-regions of East China. Int. J. Climatol 35 (9), 2243-2257. doi:10.1002/joc.4145

Sun, B., and Wang, H. (2014a). Moisture Sources of Semiarid Grassland in China Using the Lagrangian Particle Model FLEXPART. J. Clim. 27 (6), 2457-2474. doi:10.1175/jcli-d-13-00517.1

Sun, B., Zhu, Y., and Wang, H. (2011). The Recent Interdecadal and Interannual Variation of Water Vapor Transport over Eastern China. Adv. Atmos. Sci. 28, 1039-1048. doi:10.1007/s00376-010-0093-1

Sun, L., Shen, B., Sui, B., and Huang, B. (2017). The Infuences of East Asian Monsoon on Summer Precipitation in Northeast China. Clim. Dyn. 48 (5-6), 1-13.
Tian, B., and Fan, K. (2013). Factors Favorable to Frequent Extreme Precipitation in the Upper Yangtze River Valley. Meteorol. Atmos. Phys. 121, 189-197. doi:10.1007/s00703-013-0261-9

Trenberth, K. E. (1999). Atmospheric Moisture Recycling: Role of Advection and Local Evaporation. J. Clim. 12, 1368-1381. doi:10.1175/1520-0442(1999) 012<1368:amrroa $>2.0$. co; 2

Trenberth, K. E., Fasullo, J. T., and Mackaro, J. (2011). Atmospheric Moisture Transports from Ocean to Land and Global Energy Fows in Reanalyses. J. Climate 24 (18), 4907-4924.

Viste, E., and Sorteberg, A. (2013). Moisture Transport into the Ethiopian highlands. Int. J. Climatol. 33, 249-263. doi:10.1002/Joc.3409

Wang, B., and Fan, Z. (1999). Choice of South Asian Summer Monsoon Indices. Bull. Amer. Meteorol. Soc. 80, 629-638. doi:10.1175/1520-0477(1999)080<0629: cosasm $>2.0 . \mathrm{co} ; 2$

Wang, B., Wu, R., and Lau, K. M. (2001). Interannual Variability of the Asian Summer Monsoon: Contrasts between the Indian and the Western North Pacific-East Asian Monsoons*. J. Clim. 14, 4073-4090. doi:10.1175/15200442(2001)014<4073:ivotas $>2.0 . c 0 ; 2$

Wang, B., Wu, Z., Li, J., Liu, J., Chang, C. P., Ding, Y., et al. (2008). How to Measure the Strength of the East Asian Summer Monsoon. J. Clim. 21, 4449-4463. doi:10.1175/2008jcli2183.1

Wang, H. J., and Chen, H. (2012). Climate Control for southeastern China Moisture and Precipitation: Indian or East Asian Monsoon. J. Geophys. Res. Atmos. 117 (D12), 48-50. doi:10.1029/2012jd017734

Wei, J., Dirmeyer, P. A., Bosilovich, M. G., and Wu, R. (2012). Water Vapor Sources for Yangtze River Valley Rainfall: Climatology, Variability, and Implications for Rainfall Forecasting. J. Geophys. Res. 117, D05126. doi:10.1029/2011JD016902

Yatagai, A., and Yasunari, T. (1995). Interannual Variations of Summer Precipitation in the Arid/semi-Arid Regions in China and Mongolia : Their Regionality and Relation to the Asian Summer Monsoon. J. Meteorol. Soc. Jpn. 73, 909-923. doi:10.2151/jmsj1965.73.5_909

Zhang, L., and Zhou, T. (2015). Drought over East Asia: a Review. J. Clim. 28 (8), 3375-3399. doi:10.1175/jcli-d-14-00259.1

Zhang, R. N., Sun, C., and Li, W. (2018). Relationship between Summer Eurasian Teleconnection and the Interannual Variations of Arctic Sea Ice and Associated Influence on Summer Precipitation over China. Chin. J. Geophys. 61, 91-105. doi:10.6038/cjg2018K0755

Zhao, P., Zhang, R., Liu, J., Zhou, X., and He, J. (2007). Onset of Southwesterly Wind over Eastern China and Associated Atmospheric Circulation and Rainfall. Clim. Dyn. 28, 797-811. doi:10.1007/s00382006-0212-y

Zhou, L. T. (2011). Impact of East Asian winter Monsoon on Rainfall over southeastern China and its Dynamical Process. Int. J. Climatol. 31, 677-686. doi:10.1002/joc.2101

Zhou, T. J., and Yu, R. C. (2005). Atmospheric Water Vapor Transport Associated with Typical Anomalous Summer Rainfall Patterns in China. J. Geophys. Res. Atmos. 110 (D8), 211. doi:10.1029/2004jd005413

Zhu, Y., Wang, H., Zhou, W., and Ma, J. (2011). Recent Changes in the Summer Precipitation Pattern in East China and the Background Circulation. Clim. Dyn. 36, 1463-1473. doi:10.1007/s00382-010-0852-9

Conflict of Interest: The authors declare that the research was conducted in the absence of any commercial or financial relationships that could be construed as a potential conflict of interest.

Publisher's Note: All claims expressed in this article are solely those of the authors and do not necessarily represent those of their affiliated organizations, or those of the publisher, the editors and the reviewers. Any product that may be evaluated in this article, or claim that may be made by its manufacturer, is not guaranteed or endorsed by the publisher.

Copyright $\odot 2021$ Zhang, Chu, Zuo and Qi. This is an open-access article distributed under the terms of the Creative Commons Attribution License (CC BY). The use, distribution or reproduction in other forums is permitted, provided the original author(s) and the copyright owner(s) are credited and that the original publication in this journal is cited, in accordance with accepted academic practice. No use, distribution or reproduction is permitted which does not comply with these terms. 